\title{
Learned Food Aversion: A Component of Anorexia Syndromes
}

\author{
Ilene L. Bernstein \\ University of Washington
}

\author{
Soo Borson \\ Department of Psychiatry and Behavioral Sciences, \\ University of Washington and \\ Seattle Veteran's Administration Medical Center
}

\begin{abstract}
Several syndromes that have been characterized in terms of anorexia or appetite loss may actually be due, at least in part, to specific food aversion learning. Evidence reviewed here indicates that a number of experimental treatments, such as tumor implant and subdiaphragmatic vagotomy, that lead to anorexia in laboratory animals also lead to the development of specific aversions to the single available diet. These aversions appear to be responsible for a significant proportion of the ensuing reduction in food intake and body weight. The case for learned food aversions as a contributing factor in clinical problems of appetite loss is more speculative. However, there are certain clinical situations that provide the expected conditions for significant food aversion learning. A careful examination of dietary patterns of patients with these disorders is proposed as a first step toward evaluating the hypothesis that aversion learning is involved in the etiology or maintenance of clinically important anorexia.
\end{abstract}

The physiological mechanisms regulating food intake have been the focus of productive investigation over the past two decades. One goal of this research has been to enhance our understanding of basic mechanisms of energy regulation and to apply this knowledge to the treatment of clinical disorders of appetite. Much of this work has been directed at identifying the causes of obesity and developing effective treatments. However, the loss of appetite and weight is also a significant and prevalent medical problem that arises in a wide variety of clinical situations. There has, to date, been relatively little success in understanding the pathophysiology of serious appetite and weight loss, and treatment has depended on relatively drastic measures such as prolonged intravenous or intragastric feeding. Interventions grounded in an understanding of the mechanisms by which undernutrition develops could, in theory, offer promise of improved outcome.

In general, the study of the physiological mechanisms responsible for the regulation of appetite has delimited one research domain. A separate line of inquiry has been the study of conditioned taste aversions, with an emphasis on defining basic Pavlovian conditioning mechanisms (Barker, Best, \& Domjan, 1977). Because these two areas of investigation differ markedly in focus, there has been relatively little interchange between them. However, in both types of studies, a change in ingestive behavior in response to an experimental manipulation is the main dependent variable. Therefore, it is reasonable to explore the potential contribution of taste aversion learning to the development of appetite and weight loss.

In this article we will argue that several syndromes character-

Preparation of this article was supported in part by National Cancer Institute Grant CA26419 to Ilene Bernstein.

We thank Irwin Bernstein, Robert Bolles, and Steve Woods for helpful comments on the manuscript.

Correspondence concerning this article should be addressed to Ilene L. Bernstein, Department of Psychology, NI-25, University of Washington, Seattle, Washington 98195. ized in terms of anorexia or appetite loss may be more accurately described in terms of specific food aversion learning. We will provide evidence that a number of experimental treatments leading to anorexia in laboratory animals also lead to the development of specific aversions to the single available diet and that these aversions may be responsible for a significant proportion of the ensuing reduction in food intake and body weight. We will also propose methods for determining when specific food aversions do contribute to the anorexia observed in the laboratory. We will then consider clinical situations in which appetite and weight loss are of serious concern and speculate about whether food aversion learning plays any role in the development of these symptoms. To generalize from experimental findings to an understanding of clinical problems requires examination of how a process that leads to the development of aversions to specific foods could be expected to have global impact on intake in humans who, unlike laboratory rats, have relatively unrestricted diet choice. Pervasive symptoms and the prompt development of numerous and wide-ranging food aversions would need to occur in humans if food aversions were to lead to reduced food intake and body weight. This issue will be addressed in detail in a subsequent section. We begin with a brief review of typical taste aversion learning and food intake paradigms.

\section{Basic Observations}

\section{Taste Aversion Learning}

Garcia and colleagues (Garcia, Ervin, \& Koelling, 1966; Garcia \& Koelling, 1966) reported that when animals eat a particular food before receiving a drug or radiation treatment that induces gastrointestinal discomfort, they will subsequently avoid that food. This response has been termed a learned taste aversion and apparently occurs because toxic symptoms induced by the treatment become associated with the food, producing a negative preference shift or learned distaste for that food. This very robust learning has been a challenge to theorists because 
it is acquired extremely rapidly (in one trial) and resists the introduction of lengthy delays between conditioned stimulus (CS; the taste) and unconditioned stimulus (UCS; the discomfort or illness). Review articles, edited volumes, and bibliographies on this subject are available to the interested reader (Barker et al., 1977; Braveman \& Bronstein, 1985; Garcia, Hankins, \& Rusiniak, 1974; Logue, 1979; Riley \& Clarke, 1977). For present purposes, it is important to note that this literature, emphasizing the stimulus-response characteristics of this learning, does not typically examine long-term consequences of aversion conditioning on food intake or regulation of body weight. ${ }^{1}$

\section{Regulation of Food Intake}

A comprehensive review of recent work examining regulation of food intake and body weight is beyond the scope of this article. However, it has become clear that the hypothalamus, though a major regulator of energy metabolism, is not the only neural structure important in control of food intake. Regions in the brain stem, the peripheral autonomic nervous system, and gut hormones have all been implicated in the control of hunger and satiety. For example, interest in the role of the vagus nerve has been stimulated by reports that the integrity of the vagus is necessary for the manifestation of the ventromedial hypothalamic obesity syndrome (Powley \& Opsahl, 1974). The area postrema, in the caudal brain stem, has also been the focus of interest because lesions in this region are associated with depressions of food intake and body weight (Contreras, Fox, \& Drugovich, 1982; Edwards \& Ritter, 1981; Hyde \& Miselis, 1983). In general, then, a wide array of experimental treatments, including brain lesions, depletion of certain neurotransmitters, hormone injections, and vagotomy, decrease food intake and/or body weight (Kissileff \& Van Itallie, 1982; Lytle, 1977). These findings imply that food intake is controlled by an enormously complex and redundant system, with a host of chemicals involved in satiety and a multitude of neural structures that can activate feeding. Alternatively, the alterations in food intake generated by some of these treatments may actually be secondary to the development of learned aversions to the available diet.

\section{Learned Food Aversions in Experimental Disorders of Food Intake}

Most studies of regulation of food intake in animals use caloric intake and/or body weight as outcome measures, and more often than not, the food offered is a single complete diet, such as commercial laboratory chow or a chemically defined diet. Reductions in daily food intake or body weight are designated hypophagia or anorexia (Novin, Wyrwicka, \& Bray, 1976; Teitelbaum \& Epstein, 1962). ${ }^{2}$

We propose that because of the way in which typical experiments on food intake regulation are designed, treatments that lead to anorexia may exert their effects not by producing a general loss of appetite but by inducing a specific conditioned aversion to the available diet. In other words, when a treatment produces symptoms that can act as UCSs for food aversion learning, a strong dislike for the available food will develop. If this now aversive diet is the only food available, lowered food intake and loss of weight will result. This is not a new idea; it was con- vincingly proposed as an explanation for certain nutrient-deficiency anorexias by Rozin and Kalat (1971). The first symptoms of thiamine deficiency in the rat are anorexia and weight loss (Rozin, 1967b). Rozin (1967a) reported that rats deficient in thiamine develop an aversion to the freely available deficient diet. This aversion is indicated by their spillage of the diet (normal rats often spill unpalatable foods) and by a strong, often $100 \%$ preference for any new diet offered to them in opposition to the standard thiamine-deficient diet. Furthermore, anorexic symptoms disappeared precipitously when a new diet was offered. These results indicated that the anorexia characteristic of many deficiencies reflects, at least in part, a learned aversion to the deficient diet. Although these findings have been well accepted, there has been little subsequent research in the area of nutrient deficiencies, and these ideas have not been extended beyond the nutrient-deficiency paradigm.

We have recently identified a number of experimental anorexias in which to some degree the reduced food intake is attributable to the development of learned aversions. These examples will be described below, but first we address two important questions: First, what is the evidence that changes in specific taste preferences can lead to global, sustained reductions in food intake? Second, how can we distinguish experimentally between general appetite loss and a specific learned food aversion?

\section{Evidence That Learned Taste Aversions Can Lead to Reductions in Food Intake}

We are proposing that symptoms of prolonged discomfort (UCSs) can become associated with the available food (CS) and lead to anorexia as well as learned food aversions. This type of CS-UCS exposure departs from the usual taste-aversion conditioning experiment, in which exposures typically last for minutes or hours rather than days. In a paradigm developed to examine whether food aversion learning can be induced under such conditions (Bernstein \& Goehler, 1983a), a chronic UCS was introduced by infusing a concentrated solution of lithium chloride $(\mathrm{LiCl})$ over an 8-day period at the rate of $1 \mu \mathrm{l} / \mathrm{hr}$ through implantable infusion pumps. The $\mathrm{CS}$ was a specific diet presented just prior to implantation of the pumps and available continuously throughout the study. The experimental questions evaluated by this design were whether learned aversions to the diet would arise without any explicit temporal pairing of the CS and UCS and whether such aversions would lead to lowered food intake.

To examine whether learned aversions themselves can cause anorexia, we need to distinguish between depressions in food intake that are the direct result of the $\mathrm{LiCl}$ infusion and those that are secondary to the development of learned aversions. This

\footnotetext{
1 Taste aversion studies typically use flavored fluids as the taste CSs and spartan water deprivation regimens (often as little as 10-15 min of fluid access a day); aversions are assessed in brief one- or two-bottle tests.

${ }^{2}$ Anorexia is a term that actually means loss of appetite. Morrison (1982) has argued against the use of the term because it implies that the cause of declines in food intake is a loss of appetite, although all that is really known is that food intake is low. We agree that hypophagia more accurately describes the behavior observed, but because the former term is in much wider usage we have used it here.
} 


\begin{tabular}{|c|c|c|}
\hline & $\begin{array}{c}\text { NOVEL FOOD } \\
(\mathrm{C}-21)\end{array}$ & $\begin{array}{c}\text { FAMILIAR FOOD } \\
\text { (Wayne Chow) }\end{array}$ \\
\hline $\begin{array}{c}\text { DRUG } \\
\text { (LICI } \\
\text { infusion) }\end{array}$ & $\begin{array}{c}\text { novel-drug } \\
\text { group }\end{array}$ & $\begin{array}{c}\text { chow-drug } \\
\text { group }\end{array}$ \\
\hline $\begin{array}{c}\text { CONTROL } \\
\text { (no } \\
\text { infusion) }\end{array}$ & $\begin{array}{c}\text { novel-contral } \\
\text { group }\end{array}$ & $\begin{array}{c}\text { chow-control } \\
\text { group }\end{array}$ \\
\hline
\end{tabular}

Figure 1. Outline of diet-novelty paradigm with chronic infusions of $\mathrm{LiCl}$. (Following 6 days on assigned diets, animals received a preference test offering a choice between their target diet and a novel alternative.)

distinction is necessary because $\mathrm{LiCl}$ and most UCSs capable of supporting taste aversion learning will cause transient perturbations of food and water intake. To separate associative from nonassociative effects of $\mathrm{LiCl}$ infusion, we compared the food intake of animals consuming their familiar maintenance diet to that of those consuming a novel diet (see Figure 1). Familiar tastes are relatively resistant to the development of learned food aversions, whereas novel tastes rapidly become the target of such aversions (Kalat, 1974; Revusky \& Bedarf, 1967). Thus, even though drug infusions were the same in both groups, the likelihoods of forming strong aversions were quite different, because the group with a novel diet had a more salient target.

A potential problem with this design is that gastrointestinal distress has been shown to induce "enhanced neophobia," an exaggerated suspicion of novel foods that is nonassociative and persists only while the animals are ill (Domjan, 1977). Greater depressions of food intake in the group with the novel diet could either be due to learned food aversions (an associative phenomenon) or to enhanced neophobia. However, preference testing involved offering the animals a choice between the target diet and one that they had never tasted before. Results of the preference test, then, allowed us to distinguish between nonspecific avoidance of all novel edibles and the development of specific aversions to a target diet associated with illness.

Food intake over the drug infusion period, as seen in Figure 2 , revealed striking differences between drug-treated animals fed novel as opposed to familiar diets. Drug infusions lowered food intake substantially more in animals consuming a novel diet than in those consuming familiar laboratory chow. Aversions were assessed by comparing target diet preference in drugtreated animals to that of controls. Significant aversions to the target diet were evident after the diet-drug association in the novel-drug group but not the chow-drug group. Because the alternate diet in the preference test was even more novel than the novel target diet, it does not appear that nonassociative enhanced neophobia was responsible for the aversions and anorexia in the novel-drug group. Rather, the severity of anorexia in the novel-drug group relative to the chow-drug group is likely to be attributable to the contribution of learned food aversions.

These findings provide evidence that learned aversions can be acquired in a situation where exposure to the CS is continuous and the UCS is chronic. Though this paradigm contrasts sharply with the usual design of learned taste aversion experi- ments, the demonstration of significant aversions to the novel but not the familiar food indicates important commonalities between the two procedures. Hence, these results indicate that, when experimental treatments produce chronic illness, the association of that illness with the available diet (particularly if it is relatively novel) fits a model of aversion conditioning.

The learning just described is quite unusual because it appears to lack any temporal association between CS and UCS. Are there hidden mechanisms that introduce temporal pairing? Because the animal is actually exposed to the CS (taste) in temporal association with meals, it is possible that discomfort arises or intensifies after meals. Such a relationship was postulated for the syndrome of thiamine deficiency, where the vitamin's role in carbohydrate metabolism provided the basis for discomfort associated with the consumption of carbohydrate (thiamine-deficient) meals (Rozin, 1967b). Other chronic UCSs (such as $\mathrm{LiCl}$ infusions) do not lend themselves readily to an explanation that retains temporal contiguity, although it remains possible that chronic symptoms are exacerbated by eating.

In addition to demonstrating that aversions arise in this situation, these results show that such aversions can lead to significant anorexia and weight loss. In this study the $\mathrm{LiCl}$ dose combined with a very slow infusion rate provided a situation where direct effects of the drug infusions on food intake were minimal. Thus, rats infused with $\mathrm{LiCl}$ and eating lab chow did not eat much less than controls. However, $\mathrm{LiCl}$ malaise (the UCS), which by itself altered food intake little, was sufficient to produce significant food aversions when associated with a novel food as the sole available diet. Furthermore, under conditions that fostered aversion conditioning, anorexia was severe and prolonged.

\section{Experimental Approaches for Distinguishing Between General Appetite Loss and Specific Food Aversions}

Because learned food aversions can arise when an experimental treatment leads to chronic discomfort or malaise, and be-

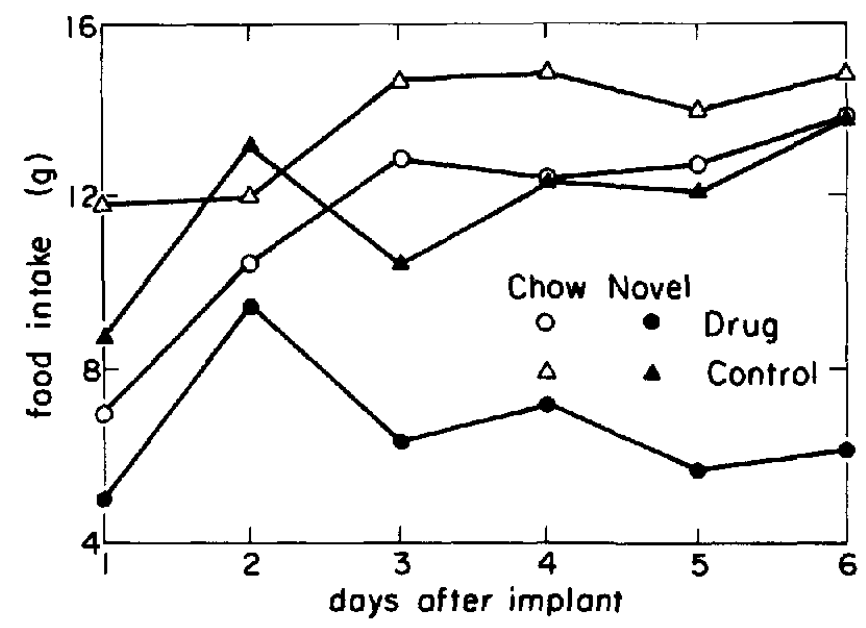

Figure 2. Mean daily food intake during $\mathrm{LiCl}$ infusions (drug) or no infusions (control). (Groups were consuming either C-21 diet [novel] or familiar Wayne lab chow [chow] adapted from Bernstein \& Goehler, 1983a.) 
cause these aversions can produce a syndrome that looks like anorexia or appetite loss, experimental approaches are needed that will allow investigators to distinguish between general appetite loss and learned food aversions. Three experimental approaches that can provide evidence implicating learned food aversions in anorexia are described below.

1. Altered diet preference after putative aversion conditioning. In this type of experiment, animals receive a novel diet for an exposure period ranging from 6 days to 3 weeks. We refer to this diet as the target diet because, as the only novel taste in this situation, it is a likely target for the development of learned aversions. A 24-hr preference test is then administered with a choice between the target diet and a novel alternative that, for naive subjects, is of comparable palatability. No food or water deprivation procedures are employed. Aversions are indicated by a significantly lower preference for target diet in experimental animals than in controls. A counterbalanced diet design is optimal, with Diet $A$ as the target diet for half the animals and Diet $B$ the target diet for the other half. If the choice during the preference test for all animals consists of Diet A versus Diet B, this design provides a built-in control for the possibility that aversions are the result of direct effects of experimental treatments on taste preference rather than specific learned associations. Learned aversions will be specific to the target diet history of the animals.

2. Reversal of anorexia by exposure to a nonaversive diet. At the end of a typical diet exposure period, food intake of experimental animals will be low relative to controls. If aversion to the target diet contributes to anorexia, the introduction of a nonaversive alternative should lead to a prompt elevation of intake. With a persistent UCS, learned aversions will eventually arise to the alternative diet so that elevations of intake are likely to be transient. On the other hand, frequent replacement of aversive diets ought to minimize the impact of learned food aversion on food intake.

3. Magnitude of anorexia as a function of novelty of the available food. As illustrated in the experiment with chronic $\mathrm{LiCl}$ infusions, learned aversions arise much more readily to a novel than to a familiar diet. We would therefore predict that experimental treatments in which learned food aversions contribute significantly to a reduction in total food intake and weight will evoke significantly greater "anorexic" effects when a novel diet is available than when animals are eating lab chow. On the other hand, when treatments affect intake by directly suppressing appetite, reduced intake should be independent of the familiarity of the diet. Our own studies have incorporated preference testing with novel alternatives to distinguish between nonassociative neophobia and specific learned aversions. Specific studies described below will serve to illustrate situations where aversions have been shown to contribute to anorexia syndromes.

\section{Tumor Anorexia}

Declines in food intake and body weight frequently accompany tumor growth (Garattini et al., 1980; Morrison, 1976). Although many hypotheses have been advanced to explain this syndrome, the mechanisms responsible remain essentially unknown. Most approaches to this problem focus on direct effects that the tumor may have on appetite via, for example, derangements in serotonin synthesis or hormone production (Krause,

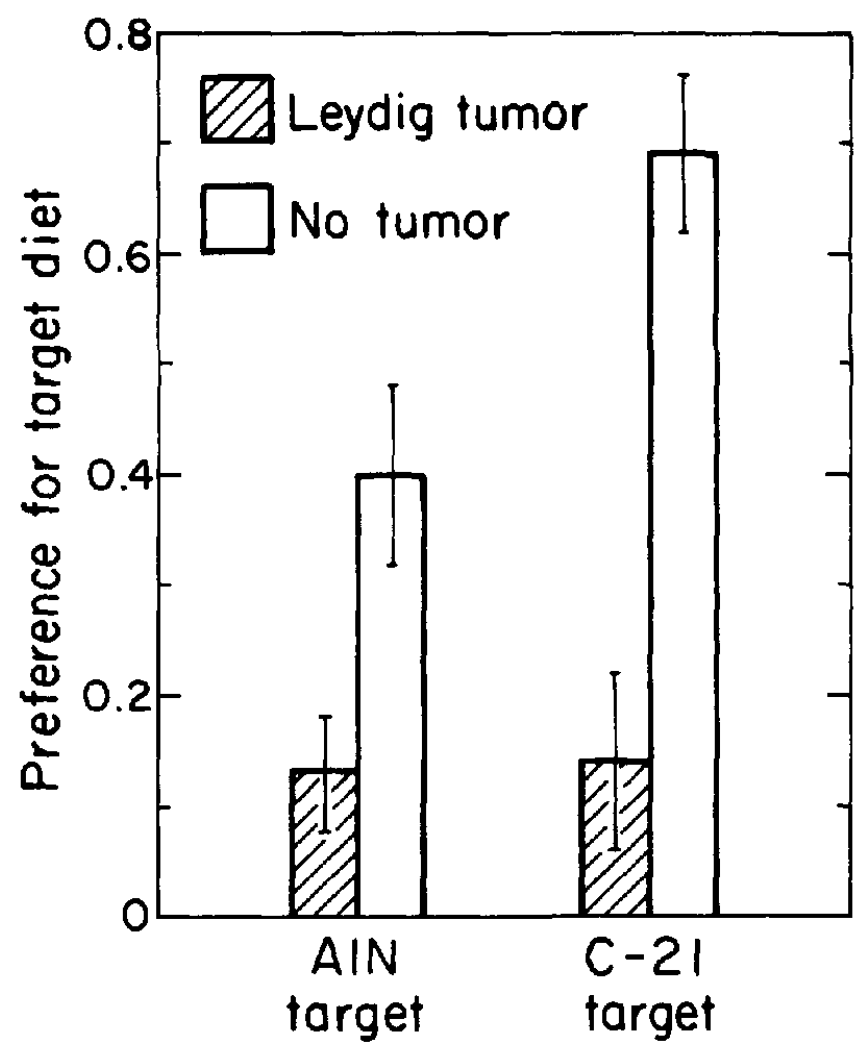

Figure 3. Average preference ( \pm standard error) for target diet in animals with Leydig LTW(m) tumors and in controls (Preference testing consisted for offering all animals both AIN and C-21 diets for $24 \mathrm{hr}$. Preference scores for the target diet [diet associated with tumor growth] were calculated by dividing consumption of target diet during the preference test by total food consumption during that period. From "Learned Food Aversions: Heterogeneity of Animal Models of Tumor-Induced Anorexia" by I. L. Bernstein and D. P. Fenner, 1983, Appetite, 4, p. 83. Copyright 1983 by Academic Press. Reprinted by permission.)

James, Ziparo, \& Fischer, 1979; Mordes \& Rossini, 1981). It is clear, however, that one component of the syndrome, at least for some experimental tumors in rats, is the development of learned aversions to the available diet (Bernstein \& Fenner, 1983; Bernstein \& Sigmundi, 1980). Rats implanted with experimental tumors (e.g., PW-739; Leydig LTW[m]) were shown to develop anorexia, weight loss, and strong aversions to the specific diet available after implant. Preference test results from a counterbalanced diet study with Leydig LTW(m) tumors illustrate these findings (Figure 3). Striking depressions in target diet preference can be seen in tumor-bearing animals relative to controls after a 19-day exposure period with either American Institute of Nutrition (AIN) or C-21 diet as their target diet. Food intake in tumor-bearing groups increased during the preference test when an alternate food was available.

The hypothesis that learned aversions contribute substantially to tumor-induced anorexia predicts that animals eating a familiar diet will display less hypophagia than those eating a novel diet, a result not implied by explanations of tumor anorexia that emphasize direct effects of tumor on appetite. When we compared tumor-bearing rats consuming a novel diet to those consuming a familiar diet, we found that animals con- 


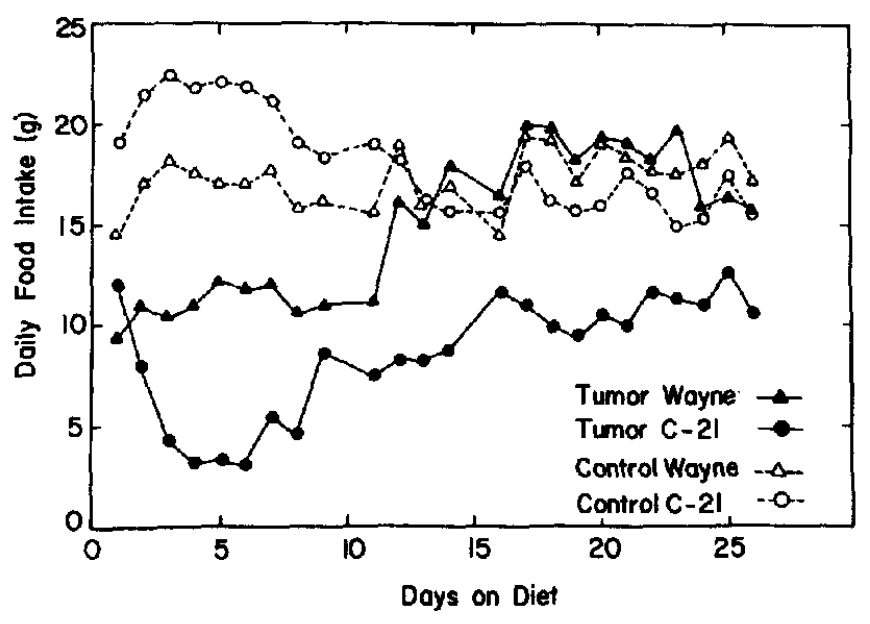

Figure 4. Mean daily food intake of PW-739 tumor-bearing and control animals. (Wayne diet was familiar; C-21 was novel.)

suming familiar laboratory chow did not develop aversions to it and had relatively mild anorexia. In contrast, animals consuming a novel diet developed strong aversions to that specific diet and displayed severe anorexia (Bernstein, Treneer, Goehler, \& Murowchick, 1985). Thus, dramatic effects of diet novelty on severity of anorexia appear to be indicative of a role for learned food aversions in this syndrome (Figure 4).

In another study the effect of diet variety was examined by introducing a different food every 3 days. Frequent changes in the diet available to tumor-bearing rats led to significantly greater food intake than the presentation of a single (initially highly palatable) food for the entire period. The influence of diet variety in tumor-bearing animals was substantially greater than was seen in controls. Apparently, when learned food aversions were prevented, or aversive foods were replaced by new ones, the impact of learned food aversions (LFAs) on food intake of tumor-bearing animals was minimized.

\section{Subdiaphragmatic Vagotomy}

Renewed interest in the role of the vagus nerve in regulation of food intake has been generated by reports that subdiaphragmatic vagotomy produces hypophagia and weight loss in normal rats (Novin, 1976; Opsahl \& Powley, 1977) and can reverse the hyperphagia and obesity of rats with ventromedial hypothalamic (VMH) lesions (Powley \& Opsahl, 1974). It is necessary to consider whether these effects are based on specific regulatory functions of the vagus nerve or (at least in part) on nonspecific effects of vagotomy surgery. Vagotomy can produce symptoms of nausea and discomfort, symptoms that are highly effective UCSs in food aversion conditioning (Kennedy, 1974; Roberts, 1967). Could some of the depression in food intake observed in rats with vagotomy be due to the development of aversions to the foods eaten after surgery? Recently in our laboratory (Bernstein \& Goehler, 1983b) we found that significant aversions developed to novel target diets consumed after vagotomy surgery. Additionally, when effects of vagotomy on animals consuming novel and familiar diets were compared, reductions in food intake were more long lasting and severe in animals with the novel diet. Significant aversions were evident in animals with a novel but not a familiar diet.

Apparently, learned food aversions can contribute to the appetite and weight loss exhibited by vagotomized animals, with the magnitude of this contribution depending on procedural details such as diet familiarity and recovery time. ${ }^{3}$ When animals are permitted several weeks to recover from surgery before target diet exposure, learned aversions do not occur. These findings suggest that the aversive symptoms which follow vagotomy surgery are considerably reduced within 3 weeks of the surgery.

Taken together, our results suggest that the contribution of aversions to the vagotomy syndrome would be maximized when little time is allowed for recovery from the acute effects of vagotomy surgery and when animals are offered a novel diet. It is apparently routine in some laboratories to offer vagotomized animals foods such as sweetened condensed milk soon after surgery to reduce postsurgical weight loss. Our hypothesis would predict that such procedures might worsen rather than minimize postsurgical weight loss. In fact, Snowdon and Wampler (1979) observed body weight deficits in vagotomized rats eating a liquid diet or a wet mash diet (which were both novel diets), whereas no body weight deficits were seen in rats eating familiar Wayne chow pellets.

Consideration of food aversions after vagotomy may shed some light on the role of the vagus in the expression of ventromedial hypothalamic hyperphagia. Some investigators report total reversal of VMH obesity by vagotomy (Gold, Sawchenko, DeLuca, Alexander, \& Eng, 1980; Powley \& Opsahl, 1974 Rowland \& Engle, 1978), and others report that VMH obesity does develop in vagotomized rats (Grossman, 1984; King, Carpenter, Stamoutsos, Frohman, \& Grossman, 1978; Wampler \& Snowdon, 1979). Sclafani and colleagues (Sclafani, Aravich, \& Landman, 1981) reported that the effects of vagotomy on VMH hyperphagia may be dependent on the type of diet available. In particular, they found that when offered a selection of palatable foods in addition to chow, VMH-vagotomized animals overate and gained considerably more weight than sham-vagotomized animals. It can be inferred that these animals were less likely to be affected by learned food aversions because dietary variety tends to minimize the impact of learned food aversions on food intake. An exaggerated sensitivity to vagotomy symptoms in VMH-lesioned rats relative to shams, leading to more severe and long-lasting vagotomy-induced aversions, could be the basis of much or all of the effect of vagotomy on VMH hyperphagia when a single diet is available.

\section{How Does Food Aversion Learning Lead to Anorexia?}

When the only food available to eat has become the target of a learned aversion, animals reduce their intake of it to levels below those needed to maintain their body weight. What underlying mechanisms can be postulated to account for this response? One change that accompanies food aversion conditioning is a negative shift along a continuum of palatability. Evi-

\footnotetext{
${ }^{3}$ Similar observations have recently been made in rats with lesions of the area postrema (Tomoyasu \& Kenney, 1985). These findings suggest that the enhanced preference for palatable foods and some of the anorexia reported in animals with lesions of the area postrema may be due to learned aversions acquired as a consequence of the lesions.
} 
dence for this extends beyond the simple observation that intake of a CS taste is reduced in both single-choice and twochoice preference tests. Pelchat and colleagues (Pelchat, Grill, Rozin, \& Jacobs, 1983) have shown that rats consuming a sugar solution that had previously been paired with $\mathrm{LiCl}$ showed orofacial responses, such as gaping, that indicate distaste (Grill \& Norgren, 1978). Similar findings have been reported by Parker (1982). In a study with human subjects, Pelchat and Rozin (1982) found that strong distastes for foods were acquired when consumption had been associated with nausea and/or vomiting but not when foods were followed by other unpleasant events such as hives or respiratory distress. Diet palatability can influence food intake and body weight (Mrosovsky \& Powley, 1977; Peck, 1978; Sclafani \& Springer, 1976). Animals who are shifted from a diet high in palatability to a diet low in palatability will reduce their food intake and lose weight. It is therefore reasonable to hypothesize that the reductions in perceived palatability of the diet that occur as a consequence of food aversion learning contribute to anorexia.

Another mechanism to be considered involves the generation of conditioned responses after food aversion conditioning. Food aversion learning has often been conceptualized in terms of classical conditioning, and yet very few studies have actually measured a conditioned response. The usual outcome measure in conditioned taste aversion studies is a reduction in ingestion. The failure to examine conditioned responses (CRs) directly is due, in part, to the prominence of the rat as subject in these studies. Because illness, nausea, and vomiting are prevalent unconditioned responses (UCRs) in taste aversion acquisition and the rat is physically unable to vomit, no observable $C R$ is available. In fact, there is evidence that nausea is a critical event in the development of hedonic changes in food aversion conditioning (Pelchat \& Rozin, 1982; Pelchat et al., 1983).

In a species like the coyote that does vomit in response to $\mathrm{LiCl}$ or other toxic treatments, a classically conditioned response of retching to a CS (taste) has been reported by Gustafson, Garcia, Hankins, and Rusiniak (1974). A potential analogue of vomiting (and correlate of nausea) in the rat is closure of the pyloric sphincter with consequent delay of stomach emptying. This response occurs after $\mathrm{LiCl}$ and radiation treatments (Bernstein \& Lett, 1984; Hulse \& Patrick, 1977). Closure of the pyloric sphincter is an example of a physiological CR that may be triggered by each CS (food) encounter in an animal with a conditioned aversion to the available diet. One might then expect eating to be accompanied by excessive retention of food in the stomach and a sense of bloating or fullness, which could readily lead to reduced food intake. Although there is not yet any evidence of conditioning of the pyloric sphincter, there is strong evidence in humans that nausea and vomiting can be classically conditioned. This potent conditioning has been a problem for many patients receiving chemotherapy for cancer (Burish \& Carey, 1984; Morrow \& Morrell, 1982; Nesse, Carli, Curtis, \& Kleinman, 1980; Redd \& Andersen, 1981). Additionally, the observation in rats that antiemetic drugs can reduce the expression of conditioned taste aversions produced by $\mathrm{LiCl}$ suggests that nausea becomes conditioned to and triggered by taste stimuli (Coil, Hankins, Jenden, \& Garcia, 1978; but see Goudie, Stolerman, Demellweek, \& D'Mello, 1982). We suggest that aversive physiological CRs triggered by CS tastes could prove highly effective in producing anorexia. Although some- what speculative, this suggestion is compelling and experimentally testable.

Two consequences of aversion conditioning, then, may be responsible for reductions in food intake and body weight: negative shifts in the palatability of available food and conditioned physiological responses, such as nausea and delayed stomach emptying, elicited by consumption of that food.

\section{Can Learned Food Aversions Explain Cholecystokinin- Induced Satiety?}

The case made here for learned food aversions as a cause of anorexia may superficially appear similar to the controversy over the specificity of the effects of cholecystokinin (CCK) and other gastrointestinal hormones on food intake. Cholecystokinin has been proposed to act as a short-term satiety signal in the control of food intake (G. P. Smith \& Gibbs, 1979). Evidence supporting this signal function has recently been reviewed in detail (G. P. Smith, 1984). However, conditioned taste aversions have been demonstrated in experiments which pair a flavor with CCK injections (Deutsch \& Hardy, 1977). This finding raises the possibility that CCK might influence food intake, at least in part, by inducing nonspecific illness. G. P. Smith and Gibbs (1979) and G. P. Smith (1984) believe that illness is not essential for the satiety effect of the peptide, but this controversy is not yet resolved. We believe that, although malaise may sometimes be associated with CCK injections, learned aversions cannot account for the depressions of food intake typically associated with this treatment. The effects of CCK do not depend on repeated pairing of diet and hormone. In fact, the effect is seen on first exposure and therefore cannot be explained by a learning paradigm.

\section{Do Learned Food Aversions Arise With Familiar Foods?}

We have proposed that learned food aversions may make unrecognized contributions to the declines of food intake and body weight engendered by a variety of experimental treatments. We have cited clear evidence that such aversions can contribute to the anorexia provoked by certain tumors and by vagotomy surgery. On the other hand, we have also indicated that learned food aversions are not evident when the available diet is familiar lab chow (Bernstein \& Goehler, 1983a, 1983b; Bernstein et al., 1985). Does this imply that studies examining food intake and body weight in animals consuming their customary lab chow are not likely to be confounded by the effects of learned food aversions? Perhaps, although some uncertainty exists as to the likelihood of developing lab chow aversions. Anorectic animals, however, are often described as finicky, and a great many researchers provide softer, sweeter, or fattier foods to them. The exclusive use of lab chow may be one way to minimize the effects of learned food aversions on food intake in the laboratory.

Familiarization with target diets prior to beginning experimental manipulations, such as surgery or hormone injections, would seem prudent when liquid or nutritionally defined diets are important to an experimental protocol. However, the effectiveness of even lengthy preexposure is uncertain. We found that 4 weeks of preexposure to a semisynthetic, complete diet provided surprisingly little protection against the development 
of tumor-induced aversions (Bernstein et al., 1985). Thus, a moderately familiar diet was definitely not immune to aversion conditioning. It is unclear why commercial laboratory chows have proven so resistant to learned aversions in our lab, inasmuch as familiarization retards but does not eliminate aversion conditioning (Elkins, 1974). One possibility is that aversions to familiar chow were present but undetectable because a novel alternative was used to test for aversions; even aversive chow may be preferable to a new food presented to a sick or poisoned animal. Mild food aversions in familiar diet groups would not undermine the utility of the diet-novelty paradigm. Rather dietnovelty experiments might provide rather conservative estimates of the contribution of learned aversions to anorexia if they are based on the difference between two diet groups that differ in the magnitude of their aversions.

\section{Are Learned Food Aversions Clinically Relevant?}

In considering whether the learning mechanisms defined in experimental settings may be involved in the genesis of clinically important appetite loss, we must deal with obvious differences between laboratory rats and people in access to food and food choices. On the one hand, no food in a person's diet is as familiar as lab chow is to a rat that has been raised on it from weaning. This may explain why familiar foods in patients' diets can readily become the target of learned aversions when consumed before cancer chemotherapy (Bernstein, Webster, \& Bernstein, 1982). On the other hand, no food is likely to be as novel as a brand new food offered against the background of dietary monotony, which characterizes the usual laboratory rat's experience.

Our task, then, is to consider how learned aversions to specific foods or tastes can generate anorexia or the reduction of food intake in general. One feature of learned aversions that may be important is the tendency to generalize. That is, aversions acquired to one food or taste will lead to avoidance of foods that share similar taste properties (Logue, 1985; Parker \& Revusky, 1982). Additionally, aversions to one novel flavor may generalize to other flavors that are similar purely by virtue of also being novel (Best \& Batson, 1977). On this basis, then, the impact of specific aversions on food intake by individuals with access to different foods can be considerably broadened.

In spite of generalization, healthy people with very diverse diets may be buffered against the effects of learned food aversions by the variability of their diets. Certain disease states, however, can offer opportunities for taste aversion learning that are not present in the healthy condition. In some disorders, ingestion of food produces discomfort, which may act as a UCS for the development of taste aversions. In others, chronic malaise may become linked with food ingestion because it is so pervasive. Food aversions form rapidly (i.e., after one or two pairings of taste with discomfort); it is easy to imagine that longlasting discomfort could engender aversion to a broad range of foods and thereby lead to a global reduction in food intake. In addition, people with finicky appetites or narrow preference ranges before the development of an illness or whose diets are limited by medical prescription will experience frequent pairings of specific food items with symptoms of illness. This situation might lead to more probable or severe aversions. Such people may not be willing or able to make alternate, nonaversive food choices, and instead, may progressively reduce their food intake. Identifiable groups of patients who might be most vulnerable to these effects are children, whose menus are typically limited and who tend to avoid new flavors (Birch \& Marlin, 1982); older adults, whose diet choices may be limited by mechanical problems with eating or altered taste sensitivity; and patients whose diet is limited to foods of a single ethnic group. As Rozin and Rozin (1981) have noted, most of the world's cuisines are characterized by the repetitive use of particular combinations of flavorings. Thus, even though foods may vary, flavors within a single ethnic category will not, and aversions to those flavor combinations may have broad influences on food intake through generalization.

Is there reason to look for conditioned taste aversions in any human disease or to attempt nutritional intervention based on aversion learning theory? Clinical syndromes characterized by significant weight loss constitute a heterogeneous group with little superficial resemblance to each other (e.g., cancer patients and young women with anorexia nervosa). However, a closer look at the symptoms cited by patients as reasons for their diminished food intake may reveal some commonalities between these syndromes. Cancer patients and depressives with clinically significant weight loss frequently report that foods have altered in their taste quality and that they no longer taste good (DeWys, 1985; Wittenborn \& Buhler, 1979). Early satiety or bloating is reported by patients with anorexia nervosa as well as those with cancer and depressive illness (DeWys, 1985; Holt, Ford, Grant, \& Heading, 1981; Nelson, Jatlow, \& Quinlan, 1984; Wittenborn \& Buhler, 1979). Because taste preference changes and gastrointestinal symptoms are hypothesized here to be the mechanisms by which food aversion learning affects food intake, such reports may well be signs of aversive conditioning. We propose that a search for conditioned aversions is warranted when undernutrition due to undereating contributes significantly to the morbidity of a disease or its treatment or when results may add to our understanding of basic mechanisms in the regulation of food intake.

In the following section we discuss several human diseases whose features make them likely to foster aversion learning. In all but one, cancer anorexia, direct evidence implicating learned food aversions is lacking. However, the severity of the symptoms and the fact that their causes are poorly understood makes the current hypothesis worthy of closer examination.

\section{Directions for Clinical Research}

\section{Cancer Anorexia}

Appetite and weight loss are problems commonly encountered by cancer patients (Costa \& Donaldson, 1979; DeWys, 1979; Shils, 1979). Loss of appetite may stem directly from the disease or result from symptoms associated with cancer treatment. In spite of decades of research into the mechanisms responsible for these symptoms, the causes of cancer anorexia remain poorly understood (Morrison, 1976). The management of cancer anorexia and its associated wasting remains a serious problem. Substantial improvements in methods of nutritional support, such as total parenteral nutrition (intravenous feeding), have been achieved in recent years. However, these approaches have not been particularly successful with cancer pa- 
tients. It has proven difficult to replete lean body mass in anorectic cancer patients, and randomized clinical trials exploring the usefulness of this method have generally not been encouraging (Kisner, 1981). These findings give added impetus to a quest for ways of improving the voluntary oral ingestion of foods in cancer patients.

Several lines of evidence have implicated learned food aversions as a contributing factor in cancer anorexia. Initially, attention was drawn to the similarity between cancer treatments, such as certain chemotherapy drugs and radiation, and the UCSs in taste aversion studies (Bernstein, 1978; J. C. Smith et al., 1984). Clinical studies indicated that learned food aversions arise in patients receiving gastrointestinally toxic chemotherapy and that these aversions are directed at specific foods consumed before treatments (Bernstein, 1978; Bernstein \& Webster, 1980; Bernstein et al., 1982). Although evidence for druginduced food aversions is strong, it remains to be determined whether aversions arising as a consequence of cancer treatments are of clinical significance in the development of global reductions in food intake and body weight. On the other hand, the scope of this work has been broadened by asking whether learned food aversions play a more general role in cancer anorexia such that aversions arise as a consequence of the disease itself.

There is clear evidence that learned aversions arise in tumorbearing animals and that these aversions are directed at the specific food available during tumor growth (Bernstein \& Sigmundi, 1980; Bernstein \& Fenner, 1983). These aversions contribute to the depressions of food intake that accompany tumor growth, and when aversions are prevented the severity of anorexia is reduced (Bernstein et al., 1985). Although similar work has not yet been done in humans, the reports that cancer patients frequently report odor and food aversions as well as early satiety (DeWys, 1985; Nielsen, Theologides, \& Vickers, 1980 ) are consistent with a role for aversion learning in their appetite loss.

In summary, previous work with aversions induced by chemotherapy indicates that humans readily acquire learned food aversions. The animal work has shown that tumor-induced food aversions can contribute to tumor anorexia; studies are now needed to determine the conditions under which similar aversions arise in the clinical setting.

\section{Anorexia Nervosa}

Anorexia nervosa is a psychiatric disorder characterized by serious weight loss and refusal to eat. This illness frequently becomes chronic, leading to disability from starvation, and an estimated $10 \%$ of patients die of medical complications of chronic undernutrition (Borson \& Katon, 1981). In chronic cases, no treatment or combination of treatments has been shown to be consistently effective (Agras \& Kraemer, 1984; Rockwell, Nishita, \& Ellinwood, 1984). Bruch (1973), Crisp (1984), and others (Minuchin, Rosman, \& Baker, 1978; Palazzoli, 1978) have emphasized the role of maturational conflicts, abnormal family relationships, voluntary food refusal, and altered body image in the initiation of anorectic behavior. However, the maintenance of anorexia nervosa, once established, appears to involve physiological mechanisms that are incompletely understood (Casper, 1985). Furthermore, current psy- chodynamic and behavioral formulations fail to explain why some persons with these conflicts develop anorexia but most do not; some authors (see Casper, 1985) argue that an as-yet undefined physiologic abnormality exists in individuals who will later express maturational conflicts via anorexia.

Certain observations on the natural history of anorexia nervosa suggest that an unconditioned stimulus for taste aversion learning may exist in this disorder in the form of gastrointestinal discomfort. Holt et al. (1981) and Saleh and Lebwohl (1979) reported a high frequency of symptoms of early satiety, epigastric discomfort, and spontaneous vomiting of meals in anorexics and were able to demonstrate a corresponding significant delay in gastric emptying in symptomatic patients. Studies of gastric function during remission have not been reported. Such studies are needed to establish whether disordered gastrointestinal motility is a consequence of starvation or is a physiological characteristic of persons who later develop anorexia. Even if these symptoms were secondary to starvation, they could provide a basis for aversion learning that would worsen and prolong the anorexia.

Conditioned food aversions have not been systematically studied in patients with anorexia. Some patients show grossly altered diet composition and meal patterns, but the majority do not, at least when assessed by retrospective dietary interviews (Beumont, Chambers, Rouse, \& Abraham, 1981; Huse \& Lucas, 1984). Logue, Logue, and Strauss (1983) failed to find differences between anorexics and controls in frequency of selfreported food aversion learning, assessed by a retrospective mail survey. However, neither type of study can be considered conclusive. The dietary history studies are hampered by the absence of data on premorbid diet or change in pattern with remission. The Logue et al. (1983) study was designed to look only for aversions to specific foods and would probably not have revealed more generalized food aversions. Experimental research in this area is needed to assess the acquisition of specific food aversions and allow quantification of sensitivity to this learning.

\section{Depressive Illness}

Loss of appetite and weight can be salient features of severe depressive illness, particularly in older women (Berry, Storandt, \& Cyne, 1984; Dessonville, Gallagher, Thompson, Finnell, \& Lewinsohn, 1982). Little is known about the mechanisms responsible for weight loss in depression. Patients commonly report loss of appetite (Mathew, Weinman, \& Mirabi, 1981; Nelson et al., 1984), and 10\%-25\% experience nausea, vomiting, "indigestion," stomach cramps, heartburn, and bloating (Nelson et al., 1984; Wittenborn \& Buhler, 1979) while depressed. Food loses its hedonic value, and patients report dry, uncomfortable feelings in the mouth (Wittenborn \& Buhler, 1979), which may distort taste quality of foods. Animal studies suggest that these symptoms should promote the development of conditioned taste aversions, although these have not yet been looked for in depression.

Further, the possibility exists that some of the persistent illness seen in chronic depression with malnutrition is due to starvation itself. On this point, Keys and his colleagues (Keys, Brozek, Henschel, Mickelson, \& Taylor, 1950) described a depressive state in volunteers subjected to chronic partial starvation, 
which responded to refeeding. No studies have been reported on the effect of refeeding on the apathy and fatigue of patients with chronic primary depression and underweight. If improvement can be demonstrated, the role of learning mechanisms, such as conditioned food aversions, in maintaining depressive cachexia merits exploration.

\section{Intestinal Bypass and Vagotomy Surgery}

Intestinal bypass, a surgical treatment for morbid obesity, appears to facilitate weight loss by leading to reductions of food intake as well as intestinal malabsorption (Bray et al., 1977; Condon, James, Wise, \& Alpers, 1978). Sclafani, Koopmans, Vasselli, and Reichman (1978) found that jejunoileal bypass surgery in rats produced a strong conditioned taste aversion to a novel-flavored solution presented after surgery. They interpreted their results as evidence that long-lasting malaise may follow this surgery and be responsible for declines in appetite and weight. It is also likely, given appropriate target diets, that learned aversions to the available diet arise after intestinal bypass surgery and contribute to declining intake. Sclafani (1981) believes that the primary mechanism of weight loss following bypass surgery is reduction in food intake. In bypass patients, changes in taste preferences as well as altered meal patterns and food attitudes are evident (Halmi, Mason, Falk, \& Stunkard, 1981). Though a food aversion learning model has not previously been proposed to help explain the changes in bypass patients, it is clear that bypass surgery results in conditions likely to foster such learning and that hedonic changes in response to eating are frequent. It is possible that individual differences in susceptibility to postoperative learned food aversions may explain some of the currently unexplained variability in outcome of this treatment.

Vagotomy has been used as a surgical treatment for morbid obesity for a number of years (Kral, 1979). Kral (1983) has reviewed evidence that vagotomized patients significantly reduce their food intake, consume foods of lower caloric density, feel less hungry after an overnight fast, and experience certain tastes less intensely than they did before surgery. Although evident in vagotomized rats (Bernstein \& Goehler, 1983b), learned food aversions have not been looked for in vagotomized patients, but delayed gastric emptying, spontaneous decreases in the intake of sweets and fats, and weight loss (Kral, 1979, 1983) suggest that conditions for aversion learning develop after vagotomy and play a role in the success of this treatment.

\section{Conclusion}

There has been relatively little interaction between investigators examining taste aversion learning and those interested in regulation of appetite and body weight. Consequently, the possibility that learned food aversions may be involved when experimental treatments appear to impair appetite has received little attention. In laboratory studies there is strong evidence that learned food aversions are present in animals manifesting a variety of anorexia syndromes and that these aversions contribute to the severity of their symptoms. In fact, we argue that in some situations animals do not eat because they have strong conditioned aversions to the only food available and that such aversions may add to the effect of illness, persist after illness has subsided, and even arise when an illness alone would not suppress intake. Because experimenters typically do not test for learned aversions when their treatments reduce food intake, we do not yet have a clear picture of the overall contribution they make to the anorexia symptoms currently being studied in the laboratory.

The case for learned food aversions as a contributing factor in clinical syndromes of appetite loss is less well established. Because humans typically have choices in what they eat, the development of aversions to specific foods should lead to the choice of other foods. However, when symptoms are pervasive and aversion learning is rapid, a substantial proportion of the foods in a patient's normal diet may soon become targets of aversions. We have described several clinical situations in which anorexia and weight loss compromise outcome or significantly impair quality of life for patients, and where there is reason to suspect a role for taste aversion learning. For cancer anorexia, evidence for involvement of aversion learning is strong. With regard to anorexia nervosa or depressive anorexia, the case for learned food aversions is far more speculative. Nonetheless, careful examination of dietary patterns in patients with anorexia symptoms could begin an evaluation of the hypothesis that aversion learning is involved in the etiology or maintenance of clinically important anorexia.

\section{References}

Agras, W. S., \& Kraemer, H. C. (1984). The treatment of anorexia nervosa: Do different treatments have different outcomes? In A. J. Stunkard \& E. Stellar (Eds), Eating and its disorders (pp. 193-208). New York: Raven Press.

Barker, L. M., Best, M. R., \& Domjan, M. (Eds.). (1977). Learning mechanisms in food selection. Waco, TX: Baylor University Press.

Bernstein, I. L. (1978). Learned taste aversions in children receiving chemotherapy. Science, 200, 1302-1303.

Bernstein, I. L., \& Fenner, D. P. (1983). Leamed food aversions: Heterogeneity of animal models of tumor-induced anorexia. Appetite, 4, 7986.

Bernstein, I. L., \& Goehler, L. E. (1983a). Chronic LiCl infusions: Conditioned suppression of food intake and preference. Behavioral Neuroscience, 97, 290-298.

Bernstein, I. L., \& Goehler, L. E. (1983b). Vagotomy produces learned food aversions in the rat. Behavioral Neuroscience, 97, 585-594.

Bernstein, I. L., \& Lett, B. T. (1984). [Delayed gastric emptying after lithium chloride injection in rats]. Unpublished raw data.

Bernstein, I. L., \& Sigmundi, R. A. (1980). Tumor anorexia: A learned food aversion? Science, 209, 416-418.

Bernstein, I. L., Treneer, C. M., Goehler, L. E., \& Murowchick, E. (1985). Tumor growth in rats: Conditioned suppression of food intake and preference. Behavioral Neuroscience, 99, 818-830.

Bernstein, I. L., \& Webster, M. M. (1980). Learned taste aversions in humans. Physiology and Behavior, 25, 363-366.

Bernstein, I. L., Webster, M. M., \& Bernstein, I. D. (1982). Food aversions in children receiving chemotherapy for cancer. Cancer, 50, 2961-2963.

Berry, J. M., Storandt, M., \& Cyne, A. (1984). Age and sex difference in somatic complaints associated with depression. Journal of Gerontology, 39, 465-467.

Best, M. R., \& Batson, J. D. (1977). Enhancing the expression of flavor neophobia: Some effects of the ingestion-illness contingency. Journal of Experimental Psychology: Animal Behavior Processes, 3, 132-143.

Beumont, P. J. V., Chambers, T. L., Rouse, L., \& Abraham, S. F. (1981). The diet composition and nutritional knowledge of patients with anorexia nervosa. Journal of Human Nutrition, 35, 265-273. 
Birch, L. L., \& Martin, D. W. (1982). I don't like it: Effects of exposure on two-year-old children's food preferences. Appetite, 3, 353-360.

Borson, S., \& Katon, W. (1981). Chronic anorexia nervosa: Medical mimic. Western Journal of Medicine, 135, 257-265.

Braveman, N. S., \& Bronstein, P. (Eds). (1985). Experimental assessments and clinical applications of conditioned food aversions. Annals of the New York Academy of Sciences, 443, 1-441.

Bray, G. A., Greenway, F. L., Barry, R. E., Benfield, J. R., Fisher, R. L., Dahns, W. T., Atkinson, R. L., \& Schwarz, A. A. (1977). Surgical treatment of obesity: A review of our experience and an analysis of published reports. International Journal of Obesity, 1, 331-367.

Bruch, H. (1973). Eating disorders. New York: Basic Books.

Burish, T. G., \& Carey, M. P. (1984). Conditioned responses to cancer chemotherapy: Etiology and treatment. In B. H. Fox \& B. H. Newberry (Eds.), Impact of psychoendocrine systems in cancer and immunity (pp. 147-178). New York: Hogrefe.

Casper, R. C. (1985). Hypothalamic dysfunction and symptoms of anorexia nervosa. Psychiatric Clinics of North America, 7, 201-213.

Coil, J. D., Hankins, W. G., Jenden, D. J., \& Garcia, J. (1978). The attenuation of a specific cue-to-consequence association by antiemetic agents. Psychopharmacology, 56, 21-25.

Condon, S. C., James, N. J., Wise, L., \& Alpers, D. H. (1978). Role of calorie intake in the weight loss after jejunoileal bypass for obesity. Gastroenterology, 74, 34-37.

Contreras, R. J., Fox, E., \& Drugovich, M. L. (1982). Area postrema lesions produce feeding deficits in the rat: Effects of preoperative dieting and 2-deoxy-d-glucose. Physiology and Behavior, 29, 875-884.

Costa, G., \& Donaldson, S. S. (1979). Current concepts in cancer: Effects of cancer and cancer treatment on the nutrition of the host. New England Journal of Medicine, 300, 1471-1474.

Crisp, A. H. (1984). Psychopathology of anorexia nervosa: Getting the heat out of the system. In A. J. Stunkard \& E. Stellar (Eds.), Eating and its disorders (pp. 209-234). New York: Raven Press.

Dessonville, C., Gallagher, D., Thompson, L. W., Finnell, K., \& Lewinsohn, P. M. (1982). Relation of age and health status for depressive symptoms in normal and depressed older adults. Essence, 5, 99-117.

Deutsch, J. A., \& Hardy, W. T. (1977). Cholecystokinin produces bait shyness in rats. Nature, 266, 196.

DeWys, W. D. (1979). Anorexia as a general effect of cancer. Cancer, 43, 2013-2019.

DeWys, W. D. (1985). Nutritional problems in cancer patients: Overview and perspective. In T. G. Burish, S. M. Levy, \& B. E. Meyerowitz (Eds.), Cancer, nutrition, and eating behavior: $A$ biobehavioral perspective (pp. 135-148). Hillsdale, NJ: Erlbaum.

Domjan, M. (1977). Attenuation and enhancement of neophobia for edible substances. In L. Barker, M. Best, \& M. Domjan (Eds.), Learning mechanisms in food selection (pp. 151-179). Waco, TX: Baylor University Press.

Edwards, G. L., \& Ritter, R. C. (1981). Ablation of the area postrema causes exaggerated consumption of preferred foods in the rat. Brain Research, 216, 265-276.

Elkins, R. L. (1974). Conditioned flavor aversions to familiar tap water in rats: An adjustment with implications for aversion therapy treatment of alcoholism and obesity. Journal of Abnormal Psychology, 83, $411-417$.

Garattini, S., Bizzi, A., Donelli, G., Guaitani, A., Samanin, R., \& Spreafico, F. (1980). Anorexia and cancer in animals and man. Cancer Treatment Reviews, 7, 115-140.

Garcia, J., Ervin, F. R., \& Koelling, R. A. (1966). Learning with prolonged delay of reinforcement. Psychonomic Science, 5, 121-122.

Garcia, J., Hankins, W. G., \& Rusiniak, K. W. (1974). Behavioral regulation of the milieu interne in man and rat. Science, 185, 824-831.

Garcia, J., \& Koelling, R. A. (1966). Relation of cue to consequence in avoidance learning. Psychonomic Science, 4, 123-124.

Gold, R. M., Sawchenko, P. E., DeLuca, C., Alexander, J., \& Eng, R. (1980). Vagal mediation of hypothalamic obesity but not of super- market dietary obesity. American Journal of Physiology, 238, R447R453.

Goudie, A. J., Stolerman, I. P., Demellweek, C., \& D'Mello, G. D. (1982). Does conditioned nausea mediate drug-induced conditioned taste aversion? Psychopharmacology, 78, 277-281.

Grill, H. J., \& Norgren, R. (1978). The taste reactivity test: I. Mimetic responses to gustatory stimuli in neurologically normal rats. Brain Research, 143, 263-269.

Grossman, S. P. (1984). Contemporary problems concerning our understanding brain mechanisms that regulate food intake and body weight. In A. J. Stunkard \& E. Stellar (Eds.), Eating and its disorders (pp. 5-14). New York: Raven Press.

Gustafson, C. R., Garcia, J., Hankins, W. G., \& Rusiniak, K. W. (1974). Coyote predation control by aversive conditioning. Science, 184, 581-583.

Halmi, K. A., Mason, E., Falk, J. R., \& Stunkard, A. (1981). Appetitive behavior after gastric bypass for obesity. International Journal of Obesity, 5, 457-464.

Holt, S., Ford, M. J., Grant, S., \& Heading, R. C. (1981). Abnormal gastric emptying in primary anorexia nervosa. British Journal of Psychiatry, 139, 550-552.

Hulse, E. V., \& Patrick, G. (1977). A model for treating post-irradiation nausea and vomiting in man: The action of insulin in abolishing radiation-induced delay in gastric emptying in the rat. British Journal of Radiology, 50, 645-651.

Huse, D. M., \& Lucas, A. R. (1984). Dietary patterns in anorexia nervosa. American Journal of Clinical Nutrition, 40, 251-254.

Hyde, T. M., \& Miselis, R. R. (1983). Effects of area postrema/caudal medial nucleus of solitary tract lesions on food intake and body weight. American Journal of Physiology, 244, R577-R587.

Kalat, J. W. (1974). Taste salience depends on novelty, not concentration, in taste-aversion learning in the rat. Journal of Comparative and Physiological Psychology, 86, 47-50.

Kennedy, T. (1974). The vagus and the consequences of vagotomy. Medical Clinics of North America, 58, 1231-1246.

Keys, A., Brozek, J., Henschel, A., Mickelson, O., \& Taylor, H. L. (1950). The biology of human starvation. Minneapolis: University of Minnesota Press.

King, B. M., Carpenter, R. G., Stamoutsos, B. A., Frohman, L. A., \& Grossman, S. (1978). Hyperphagia and obesity following ventromedial hypothalamic lesions in rats with subdiaphragmatic vagotomy. Physiology and Behavior, 20, 643-651.

Kisner, D. L. (1981). The nutrition of the cancer patient. Cancer Treatment Reports, 65, 1-2.

Kissileff, H. R., \& Van Itallie, T. B. (1982). Physiology of the control of food intake. Annual Review of Nutrition, 2, 371-418.

Kral, J. G. (1979). Vagotomy as a treatment for morbid obesity. Surgical Clinics of North America, 59, 1131-1138.

Kral, J. G. (1983). Behavioral effects of vagotomy in humans. Journal of the Autonomic Nervous System, 9, 273-281.

Krause, R., James, J. H., Ziparo, V., \& Fischer, J. E. (1979). Brain trytophan and the neoplastic anorexia-cachexia syndrome. Cancer, 44, $1003-1008$.

Logue, A. W. (1979). Taste aversion and the generality of the laws of learning. Psychological Bulletin, 86, 276-296.

Logue, A. W. (1985). Conditioned food aversion learning in humans. In N. S. Braveman \& P. Bronstein (Eds.), Experimental assessments and clinical applications of conditioned food aversions. Annals of the New York Academy of Sciences, 443, 316-329.

Logue, A. W., Logue, K. R., \& Strauss, K. E. (1983). The acquisition of taste aversions in humans with eating and drinking disorders. $\mathrm{Be}$ havioral Research and Therapy, 21, 275-289.

Lytle, L. D. (1977). Control of eating behavior. In R. J. Wurtman \& J. J. Wurtman (Eds.), Nutrition and the brain (Vol. 2, pp. 1-45). New York: Raven Press. 
Mathew, R. J., Weinman, M. L., \& Mirabi, M. (1981). Physical symptoms of depression. British Journal of Psychiatry, 139, 293-296.

Minuchin, S., Rosman, B. L., \& Baker, L. (1978). Psychosomatic families: Anorexia nervosa in context. Cambridge, MA: Harvard University Press.

Mordes, J. P., \& Rossini, A. A. (1981). Tumor-induced anorexia in the Wistar rat. Science, 213, 565-567.

Morrison, S. D. (1976). Control of food intake in cancer cachexia: A challenge and a tool. Physiology and Behavior, 17, 705-714.

Morrison, S. D. (1982). Discussion which appeared after Bernstein (1982). Cancer Research, 42, 719S-720S.

Morrow, G. R., \& Morrell, B. S. (1982). Behavioral treatment for the anticipatory nausea and yomiting induced by cancer chemotherapy. New England Journal of Medicine, 307, 1476-1480.

Mrosovsky, N., \& Powley, T. L. (1977). Set points for body weight and fat. Behavioral Biology, 20, 205-223.

Nelson, J. C., Jatlow, P. I., \& Quinlan, D. M. (1984). Subjective complaints during desipramine treatment. Archives of General Psychiatry, 41, 55-59.

Nesse, R. M., Carli, T., Curtis, G. C., \& Kleinman, P. D. (1980). Pretreatment nausea in cancer chemotherapy: A conditioned response? Psychosomatic Medicine, 42, 33-36.

Nielsen, S. S., Theologides, A., \& Vickers, Z. M. (1980). Influence of food aversions and preferences in patients with cancer. American Journal of Clinical Nutrition, 33, 2253-2261.

Novin, D. (1976). Visceral mechanisms in the control of food intake. In D. Novin, W. Wyrwicka, \& G. Bray (Eds.), Hunger: Basic mechanisms and clinical implications (pp. 357-367). New York: Raven Press.

Novin, D., Wyrwicka, W., \& Bray, G. (Eds.). (1976). Hunger: Basic mechanisms and clinical implications. New York: Raven Press.

Opsahl, C. A., \& Powley, T. L. (1977). Body weight and gastric acid secretion in rats with subdiaphragmatic vagotomy and lateral hypothalamic lesions. Journal of Comparative and Physiological Psychology, 91, 1284-1296.

Palazzoli, M. S. (1978). Self-starvation: From individual to family therapy in treatment of anorexia nervosa. New York: Jason Aronson.

Parker, L. A. (1982). Nonconsummatory and consummatory behavioral CRs elicited by lithium- and amphetamine-paired flavors. Learning and Motivation, 13, 281-303.

Parker, L. A., \& Revusky, S. (1982). Generalized conditioned flavor aversions: Effects of toxicosis training with one flavor on the preference for different novel flavors. Animal Learning and Behavior, 10 . 505-510.

Peck, J. W. (1978). Rats defend different body weights depending on palatability and accessibility of their food. Journal of Comparative and Physiological Psychology, 92, 555-570.

Peichat, M. L., Grill, H. J., Rozin, P., \& Jacobs, J. (1983). Quality of acquired responses to tastes by rattus norvegicus depends on type of associated discomfort. Journal of Comparative Psychology, 2, 140153.

Pelchat, M. L., \& Rozin, P. (1982). The special role of nausea in the acquisition of food dislikes by humans. Appetite, 3, 341-351.

Powley, T. L., \& Opsahl, C. A. (1974). Ventromedial hypothalamic obesity abolished by subdiaphragmatic vagotomy. American Journal of Physiology, 226, 25-33.

Redd, W. H., \& Andersen, G. V. (1981). Conditioned aversion in cancer patients. Behavior Therapist, 4, 3-4.

Revusky, S. H., \& Bedarf, E. W. (1967). Association of illness with prior ingestion of novel foods. Science, 155, 219-220.

Riley, A. L., \& Clarke, C. M. (1977). Conditioned taste aversions: A bibliography. In L. M. Barker, M. R. Best, \& M. Domjan (Eds.),
Learning mechanisms in food selection (pp. 593-616). Waco, TX: Baylor University Press.

Roberts, K. (1967). The dumping syndrome. In G. B. Thompson, D. Berkowitz, \& E. Pollis (Eds.), The stomach (pp. 426-429). New York: Grune \& Stratton.

Rockwell, W. J. K., Nishita, J. K., \& Ellinwood, E. H. (1984). Anorexia nervosa: Current perspectives in research. Psychiatric Clinics of North America, 7, 223-233.

Rowland, N., \& Engle, D. J. (1978). Hypothalamic hyperphagia prevented by prior subdiaphragmatic vagotomy: Insulin hyperphagia is unaffected. Physiology and Behavior, 21, 685-689.

Rozin, E., \& Rozin, P. (1981). Culinary themes and variations. Natural History, 90, 6-14.

Rozin, P. (1967a). Specific aversions as a component of specific hungers. Journal of Comparative and Physiological Psychology, 64, 237-242.

Rozin, P. (1967b). Thiamine and specific hunger. In. C. F. Code (Eds.), Handbook of physiology: Alimentary canal (pp. 411-431). Baltimore, MD: Waverly Press.

Rozin, P., \& Kalat, J. W. (1971). Specific hungers and poison avoidance as adaptive specializations of learning. Psychological Review, 78, 459-486.

Saleh, J. W., \& Lebwohl, P. (1979). Gastric emptying studies in patients with anorexia nervosa: Effect of metoclopramide. Gastroenterology, $76,1233$.

Sclafani, A. (1981). Appetitive behavior after jejunoileal bypass. International Journal of Obesity, 5, 449-455.

Sclafani, A., Aravich, P. F., \& Landman, M. (1981). Vagotomy blocks hypothalamic hyperphagia in rats on a chow diet and sucrose solution but not on a palatable mixed diet. Journal of Comparative and Physiological Psychology, 95, 720-734.

Sclafani, A., Koopmans, H. S., Vasselli, J. R., \& Reichman, M. (1978). Effects of intestinal bypass surgery on appetite, food intake, and body weight in obese and lean rats. American Journal of Physiology, 234, E389-E398.

Sclafani, A., \& Springer, D. (1976). Dietary obesity in adult rats: Similarity to hypothalamic and human obesity syndromes. Physiology and Behavior, 17, 461-471.

Shils, M. E. (1979). Nutritional problems induced by cancer. Medical Clinics of North America, 63, 1009-1025.

Smith, G. P. (1984). Gut hormone hypothesis of postprandial satiety. In A. J. Stunkard \& E. Stellar (Eds.), Eating and its disorders (pp. 67-78). New York: Raven Press.

Smith, G. P., \& Gibbs, J. (1979). Postprandial satiety. Progress in Psychobiology and Physiological Psychology, 8, 180-242.

Smith, J. C., Blumsack, J. T., Bilek, F. S., Spector, A. C., Hollander, G. R., \& Baker, D. L. (1984). Radiation-induced taste aversion as a factor in cancer therapy. Cancer Treatment Reports, 68, 1219-1227.

Snowdon, C. T., \& Wampler, R. S. (1979). Weight and regulatory deficits in vagotomized rats: A reexamination. Behavior and Neural Biology, $26,342-353$.

Teitelbaum, P., \& Epstein, A. N. (1962). The lateral hypothalamic syndrome: Recovery of feeding and drinking after lateral hypothalamic lesions. Psychological Review, 69, 74-90.

Tomoyasu, N., \& Kenney, N. J. (1985). Attenuation of hypophagia following area-postrema ablation by continuous diet change. Neuroscience Abstracts, 11, 343.

Wampler, R. S., \& Snowdon, C. T. (1979). Development of VMH obesity in vagotomized rats. Physiology and Behavior, 22, 85-93.

Wittenborn, J. R., \& Buhler, R. (1979). Somatic discomforts among depressed women. Archives of General Psychiatry, 36, 465-471.

Received November 8, 1985 Revision received January 17,1986 . 